\title{
Pharmacist and physician perspectives on diabetes service delivery within community pharmacies in Indonesia: a qualitative study
}

\author{
Yosi Wibowo ${ }^{\mathrm{a}}$, Bruce Sunderland ${ }^{\mathrm{b}}$ and Jeffery Hughes ${ }^{\mathrm{b}}$ \\ ${ }^{a}$ Centre for Medicines Information and Pharmaceutical Care (CMIPC), Faculty of Pharmacy, University of Surabaya, Surabaya, East Java, Indonesia and

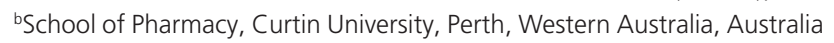

\author{
Keywords \\ barrier; community pharmacist; diabetes \\ service; facilitator; Indonesia \\ Correspondence \\ Miss Yosi Wibowo, Centre for Medicines \\ Information and Pharmaceutical Care (CMIPC), \\ Faculty of Pharmacy, University of Surabaya, J. \\ Raya Kalirungkut, Surabaya, East Java 60293, \\ Indonesia. \\ E-mail: yosi_wibowo@ubaya.ac.id
}

Received December 8, 2014

Accepted August 29, 2015

doi: 10.1111/ijpp. 12227

\begin{abstract}
Objective To explore perspectives of physicians and pharmacists on diabetes service delivery within community pharmacies in Indonesia.

Methods In depth interviews were conducted with 10 physicians and 10 community pharmacists in Surabaya, Indonesia, using a semi-structured interview guide. Nvivo version 9 was used to facilitate thematic content analysis to identify barriers/ facilitators for community pharmacists to provide diabetes services.

Key findings The identified themes indicating barriers/facilitators for diabetes service delivery within Indonesian community pharmacies included: (1) pharmacist factors - i.e. positive views (facilitator) and perceived lack of competence (barrier); (2) pharmacist-physician relationships - i.e. physicians' lack of support and accessibility (barriers); (3) pharmacist-patient relationships - i.e. perceived patients' lack of support and accessibility (barriers); (4) pharmacy environment - i.e. business orientation (barrier), lack of staff and poor pharmacist availability (barriers), and availability of supporting resources, such as counselling areas/rooms, procedures/ protocols and IT systems for labelling and patient records (facilitators); and (5) external environment - i.e. a health system to support pharmacist roles, remuneration, marketing and professional assistance (facilitators).

Conclusion Issues related to the pharmacist-physician-patient relationships, pharmacy environment and external environment need to be addressed before Indonesian community pharmacists can provide additional pharmacy services for type 2 diabetes patients. Collaboration between the Government, Ikatan Apoteker Indonesia (Indonesian Pharmacists Association) and Ikatan Dokter Indonesia (Indonesian Medical Association) is required to improve the pharmacy professional environment and facilities.
\end{abstract}

Diabetes is emerging as a chronic disease in developing countries. Indonesia is a major developing country with a population of 237.6 million. ${ }^{[1]}$ It was estimated that in 2013, 8.5 million people in Indonesia were living with diabetes, and is expected to increase to 14.1 million by $2035 .{ }^{[2]}$ In developing countries such as Indonesia, chronic diseases are currently managed in hospital outpatient or clinic settings. ${ }^{[3,4]}$ The burgeoning chronic disease burden provides an opportunity for Indonesian community pharmacists to extend their services.
Studies worldwide have explored barriers/facilitators of pharmacists to move towards a more patient-orientated model of practice. ${ }^{[5-16]}$ The majority of the studies were conducted in developed countries using questionnaires. Of those, two studies reviewed barriers/facilitators that were specific to diabetes services. Plake et al. in the USA reported that remuneration, workload and available time were perceived as the most limiting barriers. ${ }^{[12]}$ Berbatis et al. in Australia reported facilitators for diabetes service delivery included pharmacies with higher turnover and pharmacists with higher training hours, while the identified barriers were lack of confidence and the service not being regarded as 'part of the job' ${ }^{[9]}$ 
As developed countries often have a different context, translating those findings to pharmacy practice in developing countries such as Indonesia is inappropriate. In the current Indonesian health system in which physicians are the primary care providers and the concept of shared patient care is new, it is important to explore physicians' and pharmacists' perspectives regarding the potential integration of pharmacists in diabetes care. Two qualitative studies conducted in Indonesia have expressed concerns with pharmacist competencies and availability/presence in the pharmacy to provide patient care. ${ }^{[7,15]}$ This present study aimed to explore perspectives of physicians and pharmacists on diabetes service delivery within community pharmacies in Indonesia.

\section{Methods}

This study was approved by the Human Research Ethics Committee of Curtin University (PH-09-11) and Ikatan Apoteker Indonesia (IAI; Indonesian Pharmacists Association) (001/SK/BPD-IAI/SURABAYA/2010).

\section{Setting and participant recruitment}

The study was conducted in Surabaya, the second largest city in Indonesia, with approximately 3.1 million inhabitants. ${ }^{[17]}$ As factors influencing service delivery are subjective, a qualitative exploratory design was chosen for this study to understand individual viewpoints. ${ }^{[18]}$ Data were collected from in-depth interviews of physicians and community pharmacists in Surabaya, Indonesia.

Community pharmacists were recruited from respondents involved in a previous pharmacist questionnaire-based survey conducted by the first author (YW). ${ }^{[19]}$ A purposive sample of 10 pharmacists was initially selected based on the characteristics of the pharmacy premises: attachment to a medical clinic, number of patients seeking antidiabetic medications, availability of a counselling room and levels of pharmacist availability. Pharmacist availability was calculated as a ratio of total reported pharmacist working hours per week to total pharmacy opening hours per week. A ratio of one or more would indicate that there was always a pharmacist available during pharmacy opening hours. While the intention was to recruit physicians treating type 2 diabetes patients, this task was difficult as there was no available sampling frame of the specialities of physicians at medical clinics in Surabaya. Therefore, the community pharmacists involved in the interviews were asked to provide information on physicians who frequently prescribed antidiabetic medications. Ten physicians were purposively selected based on their level of practice (general practitioner (GP), specialist and endocrinologist). Pharmacists and physicians were contacted by YW either by telephone or in person to discuss the nature of the study; if they agreed to participate, an appointment for the interview was made. The initial interview target was 10 participants of each group, which was reviewed iteratively to ensure saturation was reached.

\section{Data collection}

In-depth face-to-face interviews were conducted in Bahasa Indonesia by YW (an academic pharmacist in Indonesia whose first language is Bahasa Indonesia) between May and December 2012, either within the participants' premises or in YW's office. Written informed consent was obtained. The interviews were aided by a semi-structured interview guide which was developed in conjunction with all authors and was field tested. The guide explored three areas: (1) current practice, (2) future roles, and (3) barriers/ facilitators for the provision of diabetes services (Tables 1 and 2); this paper places more emphasis on the barriers/ facilitators element of the interview guide. Probing questions were asked when necessary to expand participants' responses. A separate form was used to gather demographic details of participants and their premises. The interviews took 30-60 min and were audio-recorded. All participants were reimbursed for their time.

\section{Data analysis}

The audio-recorded interviews (Bahasa Indonesia) were transcribed verbatim. Thematic content analysis was used to identify barriers/facilitators to the service. ${ }^{[20]}$ The transcripts were coded by YW; then, the open codes were categorised and themes extracted. Examples of comments were provided to illustrate context to the themes. This involved translating the comments into English. This approach enabled the analysis to stay in the source language as long and as much as possible, thus avoiding potential limitations when analysing in another language than the source language. ${ }^{[21]}$ The themes together with the illustrative comments were reviewed by the other two authors (Professors of Pharmacy) to ensure the common sense of the interpretation. Themes and comments in Bahasa Indonesia were sent to the participants for feedback. This was used as a means of 'member-checking' to ensure credibility of the data. ${ }^{[22]}$ The data management used the NVIVo database (QSR NVIVo, version 9.0, QSR International, Melbourne Australia).

\section{Results}

Of those contacted for interviews, one pharmacist and one physician said they were too busy to participate and were replaced. Before the completion of the planned 20 interviews (i.e. after the eighth pharmacist interview and the eighth physician interview), data saturation was achieved (i.e. no new themes emerged); thus, further recruitment beyond 10 phar- 
Table 1 Interview guide - community pharmacist

Opening

The marked increase of type 2 diabetes patients in Indonesia will place pressure on health care workers to ensure optimal diabetes management. In

this situation, there is a need to make better use of health care resources in the community, including community pharmacies.

1. When a patient with type 2 diabetes visits your pharmacy, please describe services provided.

Probe/challenge them on each point in the generic model of care, starting with:

- Dispensing

- Education/counseling

- Monitoring - include monitoring compliance, monitoring treatment outcomes and adverse effects (may need to perform clinical tests, check laboratory data and/or interview the patient regarding his/her clinical problems)

- Based on the monitoring - involve in adjusting treatment plan, adjusting patient education or referring patients to other health care professionals

2. What do you think community pharmacists SHOULD do for type 2 diabetes patients?

Probe/challenge them on each point in the generic model of care, starting with:

- Dispensing

- Education/counseling

- Monitoring

- Based on the monitoring - involve in adjusting treatment plan, adjusting patient education or referring patients to other health care professionals

(If they mention services beyond dispensing)

Probe: Why do you think this (service) is important?

(If they mention no services should be provided - except for dispensing medications)

Probe: What things made you think that community pharmacists should only do dispensing?

(If the services mentioned have not done - compare point 2 to point 1)

Probe: Barriers - what things made it difficult for you to provide (the service)?

In closing

Our project is about the role of community pharmacists with respect to diabetes care. Does anything else come to mind that I haven't asked you

about?

Thank you for your participation.

Table 2 Interview guide - physician

Opening

The marked increase of type 2 diabetes patients in Indonesia will place pressure on health care workers to ensure optimal diabetes management. In this situation, there is a need to make better use of health care resources in the community. In other countries such as Australia, community pharmacists have a more active role within diabetes team, such as: repeat medications (i.e. physicians prescribe medications that allow patients to refill their medication for certain times where pharmacists ensure their diabetes control), patient education/counseling and monitoring (e.g. blood glucose level, blood pressure, weight).

1. When a patient with type 2 diabetes visits your clinic, please describe a typical consultation/assessment provided.

2. What would you like community pharmacists to do in helping your type 2 diabetes patients?

Probe/challenge them on each point in the generic model of care, starting with:

- Dispensing (how about repeat medications?)

- Education/counseling - e.g. medications, lifestyle

Then:

- Monitoring - e.g. involve in monitoring compliance, monitoring treatment outcomes and adverse effects (e.g. perform clinical tests, check laboratory data and/or interview the patient regarding his/her clinical problems)

- Based on the monitoring - e.g. involve in adjusting treatment plan, adjusting patient education or referring patients to other health care professionals

(If they mention services beyond dispensing)

Probe: Why do you think this (service) is important to be provided in the pharmacy?

(If they mention no services should be provided - except for dispensing medications)

Probe: What things made you think that community pharmacists should only do dispensing?

(We previously did surveys among patients and pharmacists, and we found areas other than dispensing that pharmacists could be involved, such as monitoring and counseling)

Probe: What do you think about that?

In closing

Our project is about the role of community pharmacists with respect to diabetes care. Does anything else come to mind that I haven't asked you about?

Thank you for your participation. 
Table 3 Characteristics of the participants and their premises

\begin{tabular}{|c|c|}
\hline Community pharmacist $(N=10)$ & \\
\hline \multicolumn{2}{|l|}{ Gender, $n$} \\
\hline Male & 2 \\
\hline Female & 8 \\
\hline Age, years (range) & $26-76$ \\
\hline \multicolumn{2}{|l|}{ Position, $n$} \\
\hline Pharmacist manager as well as owner & 4 \\
\hline Pharmacist manager & 5 \\
\hline Pharmacist employee & 1 \\
\hline Experience, years & $2-37$ \\
\hline Diabetes training, hours & $0->20$ \\
\hline \multicolumn{2}{|l|}{ Pharmacy characteristics } \\
\hline \multicolumn{2}{|l|}{ Ownership, $n$} \\
\hline Pharmacist manager as owner & 4 \\
\hline Single proprietor & 3 \\
\hline Group proprietor & 3 \\
\hline \multicolumn{2}{|l|}{ Setting, $n$} \\
\hline Within medical clinic & 5 \\
\hline Not within medical clinic & 5 \\
\hline Counselling room/area, $n$ & 5 \\
\hline Diabetes patients per month, $n$ (range) & $70-250$ \\
\hline Pharmacist availability*, ratio (range) & $0.3-2.1$ \\
\hline \multicolumn{2}{|l|}{ Physician ( $\mathrm{N}=10)$} \\
\hline \multicolumn{2}{|l|}{ Gender, $n$} \\
\hline Male & 9 \\
\hline Female & 1 \\
\hline Age, years (range) & $41-82$ \\
\hline \multicolumn{2}{|l|}{ Level, $n$} \\
\hline General practitioner (GP) & 3 \\
\hline Internal medicine specialist & 5 \\
\hline Endocrinologist/consultant & 2 \\
\hline \multicolumn{2}{|l|}{ Clinic characteristics } \\
\hline \multicolumn{2}{|l|}{ Setting, $n$} \\
\hline With on-site pharmacy & 8 \\
\hline Without on-site pharmacy & 2 \\
\hline Diabetes patients per month, $n$ (range) & $50-300$ \\
\hline
\end{tabular}

*Ratio of total pharmacist working hours per total pharmacy opening hours.

macists and 10 physicians was considered unnecessary. The characteristics of the participants and their premises are presented at Table 3. The following themes and categories of responses emerged from the analysis of the interviews (Table 4).

\section{Theme 1: pharmacist factors}

\section{Attitude}

Although all pharmacists believed that they should extend their services beyond basic dispensing, this was not supported by the majority of physicians.
As a pharmacist, we should be responsible for preparing, dispensing and providing patient counselling. That's the standard. (Pharmacist 4)

In my opinion, pharmacists should not provide anything other than what physicians have prescribed. If they find it unclear, they can check with the physician. (Physician 6)

\section{Competence}

Some of the pharmacists and physicians expressed concerns regarding pharmacists' competence to provide direct patient care.

To be honest, I do not have the courage to do it (patient care) on my own. . I am not that competent. I am afraid to fail it. (Pharmacist 3)

As I said, pharmacists have a lack of clinical knowledgethey are still product-minded-as the result of their education curriculum. (Physician 3)

\section{Theme 2: pharmacist-physician relationships}

\section{Physicians' attitude}

The majority of physicians and pharmacists expressed concerns with the involvement of pharmacists in patient care since physicians generally considered clinical activity as their role

In terms of developing a treatment plan with doctors, it will be too far ... As we can see... even in the inpatient setting, it is hard for the doctors to accept recommendations from the clinical pharmacists. (Doctor 1)

While we are trying to help ... they have accused us of encroaching on their authority. (Pharmacist 6)

These physicians' attitudes were influenced by their concerns with pharmacists' clinical knowledge (Theme 1b) and by their perceptions around the pharmacy business role; as Physician 1 illustrated: 'The pharmacist can be just an employee at the pharmacy ... if the owner is more businessoriented, they will just need the pharmacist's name to be put as a manager (and do not care for the pharmacists' professional roles)'.

\section{Physicians' accessibility}

While providing patient care requires an effective collaboration with physicians, some pharmacists and physicians expressed concerns about access to physicians due to physicians' workload. 
Table 4 Factors influencing pharmacy-based service delivery for type 2 diabetes patients as perceived by pharmacists and physicians

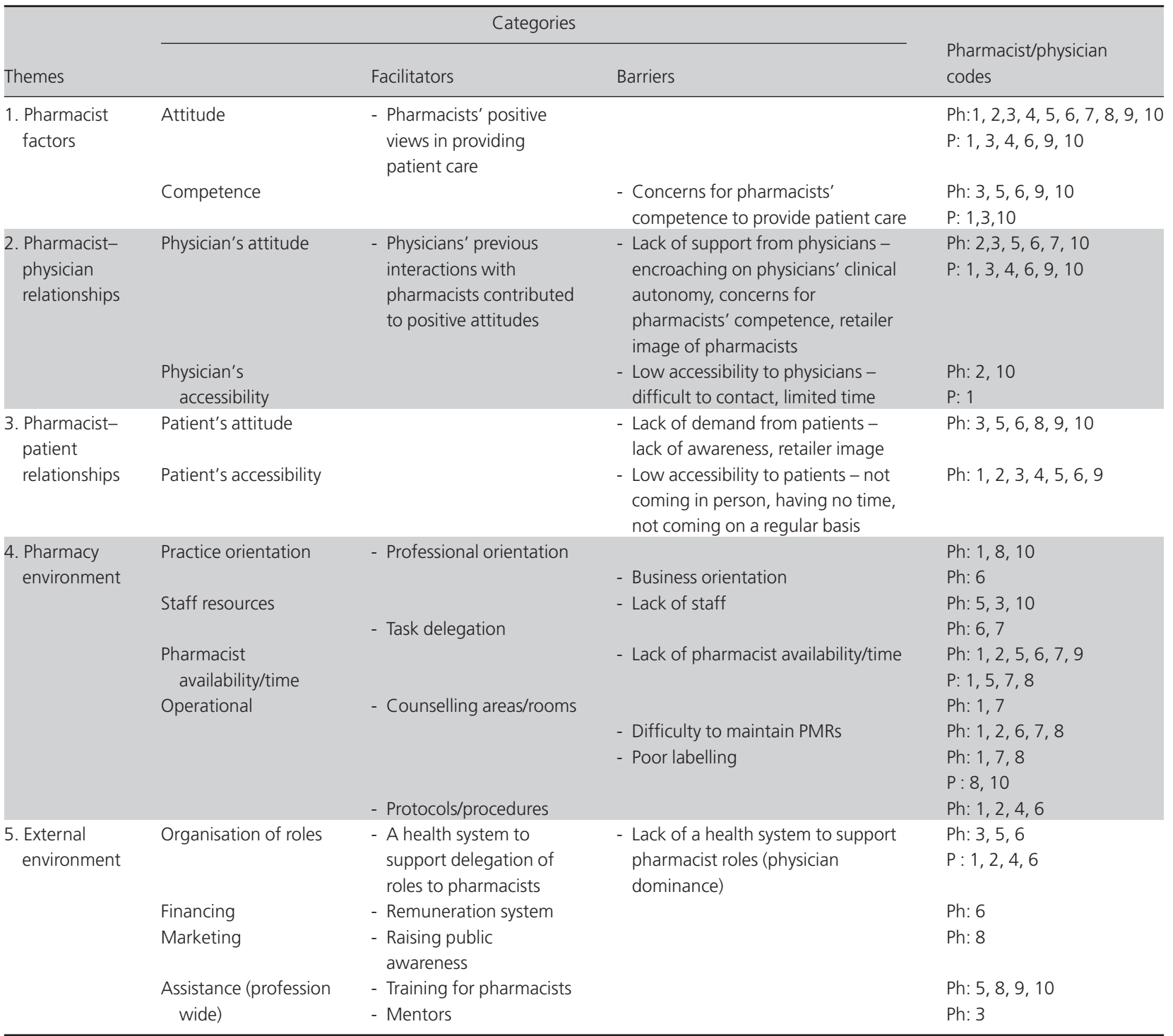

P, physician; Ph, pharmacist; PMR, patient medication record.

When we identified problems, contacting physicians was a challenge... particularly for those with lots of patients. (Pharmacist 2)

... in the primary care setting where the load is high and we should work fast, time for communication is limited. (Physician 1)

Thus, the importance of relationship building was discussed by some pharmacists and physicians to improve support from physicians. Two of the physicians had gained trust in pharmacists after working together with them over some time; as Physician 2 said: 'In my opinion, what the pharmacist " $X$ " has been doing is excellent. As I have limited ability, limited time... I guess we should appreciate others who are willing to provide more care to the patients'.

\section{Theme 3: pharmacist-patient relationships}

\section{Patients' attitude}

A majority of pharmacists stated the importance of patient demand in reinforcing practice change; as Pharmacist 8 illustrated: 'I did PMRs (Patient Medication Records) before, but not anymore, as there is no demand.' It was perceived the current lack of demand was because patients had low expec- 
tations towards a pharmacist. Perceptions around pharmacists as retailers as well as healthcare providers might also create uncertainty regarding the pharmacists' roles in patient care; as Pharmacist 3 said: 'When I told them not to purchase only two or nine tablets (explaining that otherwise the problem would recur)... they did not comply . . probably they thought that I just care to sell my products.' Physicians also indicated concerns regarding the business role of pharmacy (Theme 2a).

\section{Patients' accessibility}

Some pharmacists reported that the provision of patient care was often hampered by difficulty in accessing patients, such as them not coming in person, having no time or not coming on a regular basis. Moreover, pharmacists expressed concerns that patients could switch from one pharmacy to another on successive visits, making accuracy of PMRs and service continuity difficult. As Pharmacist 4 stated: '. . in Indonesia, (most) patients are not covered by insurance plans. They could choose whichever pharmacy they like.

Hence, it was considered important to develop a professional relationship between the pharmacist and the patient to improve support from patients. Two pharmacists reported the use of simple questions about patient medications at the first meeting, to help the patients to recognise their need. They suggested that once the patients valued the service, they would be willing to access the service; as Pharmacist 1 illustrated: 'This patient was first counselled about the use of her medication few days ago ... now she asks if she can access the service in the future.

\section{Theme 4: pharmacy environment}

\section{Practice orientation}

Some pharmacists reported that practice orientation of the pharmacy owners has influenced the provision of patient care. If owners (especially non-pharmacist owners) are unaware of the professional service, or it is not a priority, the service will be vulnerable to other business pressures; as Pharmacist 6 said: 'What they (pharmacy owners) have developed really well is accounting . . financial reports etc'. In contrast, professionally active owners shared motivation to shift towards a more professional role and did not necessarily focus on maximising profit; as Pharmacist 1 (the pharmacy owner/manager) commented: 'I told the pharmacy staff to refer patients with chronic diseases to the pharmacist ... so that they can be counselled properly'.

\section{Staff resources}

Some pharmacists wanted adequate pharmacy staff to release pharmacists' time to do patient care; as Pharmacist 5 stated:
'If I have enough staff - a lot of pharmacy assistants - I will not need to dispense medications - preparing labels and such things - that now causes me to have no time for patient care. Moreover, some pharmacists noted the importance of teamwork and task delegation in the pharmacy to support their professional development; as Pharmacist 7 illustrated: ... from accepting prescriptions to dispensing has been handled by the pharmacy assistants ... the pharmacists should be at the front (counter) directly facing the customers'.

\section{Pharmacist availability/time}

To provide patient care, about half of the physicians and pharmacists emphasised that a pharmacist needs to be available at the pharmacy during opening hours.

I have tried to provide this kind of service (patient care), but I was not always available in the pharmacy/ I also have another job at another place. (Pharmacist 2)

... the problem is that pharmacists are not always available at pharmacies. (Physician 5)

\section{Operational}

Half of the pharmacies have developed PMRs; however, obtaining complete data and utilising PMRs on a regular basis were reported to be a challenge (e.g. problems with PMR retrieval (hardcopy PMRs), lack of pharmacists' time and lack of patient access). In addition to issues with PMRs, there was lack of written information and typical pharmacy labels included limited information; as Physician 8 stated: '. . they only put on how many times patients should take the medications - before or after food - but there is no drug name and strength. Hence, it would cause a mess when patients accidentally put the medication in the wrong medication bag'.

Some pharmacists mentioned that procedures and protocols could be important to ensure consistency and quality of service. The need for a consultation area/room was discussed by a few pharmacists for personal/private issues.

\section{Theme 5: external environment}

\section{Organisation of roles}

Some pharmacists and physicians perceived that the current healthcare system has not diversified (physician dominance). Thus, it was considered to clearly define roles among physicians and pharmacists:

... the IDI (Ikatan Dokter Indonesia - Indonesian Medical Association) and the IAI - with the Government as the facilitator - should have an agreement about each 
other's roles in order to provide optimal care for diabetics, e.g. repeat dispensing. (Pharmacist 6 )

I am hoping that health professionals share the same understanding of diabetes care... Basically, I hope that patients will not be afraid of taking insulin, medications, regular control, regular SMBG, when necessary. As for this, I cannot work alone. . . (Physician 2)

\section{Funding}

While currently pharmacies have only charged a low dispensing fee, Pharmacist 6 believed that it was important for pharmacists to demonstrate their value; thus, they should be reimbursed for further services: 'Especially with the Jaminan Kesehatan Nasional - JKN (National Health Insurance) coming up ... this will clearly define physicians' and pharmacists' roles. In this case, how can't pharmacists get remuneration if we already provide services?'

\section{Marketing}

For a service to be successful, Pharmacist 8 considered the importance of a nationwide promotional activity to raise patient awareness and to help in creating demand: ... for example, raising community awareness to put demand on pharmacies to do this and that. But this should be done at the national level (structural levels of the IAI)'.

\section{Assistance (profession wide)}

Due to the perceived lack of competence to provide patient care (Theme $1 \mathrm{~b}$ ), some of the pharmacists emphasised the importance of training from the IAI and educational institutions; as Pharmacist 9 stated: ‘. . there should be training for pharmacists ... to update our knowledge ... to help us providing care for the patients'. In addition to training, Pharmacist 3 suggested mentors/advisors to assist during the implementation of the service: ‘. . If only I could collaborate with the educational institution " $X$ " (for example), I am willing to do it (patient care)... Doing it without help is hard for me'.

\section{Discussion}

This study has identified, based on pharmacist and physician perspectives, factors affecting diabetes service delivery within Indonesian community pharmacies. Some views held by pharmacists were a barrier to move towards more patient-centred practice, and many of the physicians interviewed oppose an expanded clinical role for community pharmacists. The current pharmacy and external environment issues are hampering moves towards more advanced practice. The lack of proper labelling systems, PMR systems and pharmacist availability in pharmacies are three prime areas that need to be addressed before these services can be introduced. These current perceptions may be influenced by very low pharmacist salaries related to very low dispensing fees where the addition of any further services would be perceived as either not remunerated or poorly remunerated. The status quo supports the current business-orientated model. The implementation of JKN by the Indonesian Government provides an opportunity to encourage pharmacy practice change, and where appropriate, remuneration should be established for agreed services.

There are some limitations to this study. As qualitative data are a product of views, experiences and perceptions of respondents, it can be biased if respondents are not sharing their true responses. ${ }^{[18]}$ In this case, the current lack of engagement of community pharmacists in diabetes care may mitigate some of this potential bias as respondents had no experience with the service examined. In addition, the results of this study were provided to interviewees to ensure accuracy ('member-checking'). ${ }^{[22]}$ This study used a small sample size, but it included a range of pharmacists and physicians. No new themes emerged after the eighth interview for each group (data saturation), suggesting that all possible issues had been covered. ${ }^{[18,23]}$

The consolidated criteria for reporting qualitative studies (COREQ) 32-item checklist is provided in Table S1.

While pharmacists generally indicated that they should extend their roles, they perceived a range of barriers. There were concerns with pharmacist competency in providing direct patient care. In Indonesia, to become a qualified pharmacist, it requires completion of the pharmacy undergraduate course of 4-year duration (Bachelor of Pharmacy) which is followed by 1 year of preregistration training. However, it should be noted that pharmacotherapy subjects (as a basis for providing patient care) were not incorporated in the national pharmacy curricula until 2008. ${ }^{[24,25]}$ Thus, a wide variation of pharmacotherapy knowledge is expected, particularly among earlier graduates. The limited pharmacotherapy knowledge among Indonesian community pharmacists was also reported in a previous study ${ }^{[7]}$ With the changes in pharmacy curricula, it is to be expected that all new pharmacists will receive general diabetes training as part of their undergraduate programme. While there are currently a variety of opportunistic continuing professional development courses (some of which include diabetes as a topic), the IAI should consider organising formal general diabetes training to help the earlier graduates; diabetes-specific training and an accreditation system can be developed for those seeking specialisation.

This study also indicated a perceived lack of support from physicians and patients. Thus, the IAI should consider liaising with physician organisations to discuss interactions/ relationships between physicians and community pharmacists in providing patient care. While working with physicians, pharmacists need to demonstrate their value over time to patient outcomes, allowing continued development of their professional role. It was suggested that physicians' acceptance of pharmacists' clinical role was related to the level of exposure physicians had had to those services, ${ }^{[26]}$ 
which is consistent with statements from physician interviews in this study.

The pharmacist-physician-patient relationship to develop pharmacist professional roles can be influenced by both the pharmacy and external environments. It is a government requirement that prescription medications are issued by pharmacists. ${ }^{[27,28]}$ However, this study indicated an issue with pharmacist availability in the pharmacies. This was also reported in two studies undertaken in Jakarta, Indonesia, where approximately $70 \%$ of pharmacists worked in community pharmacies as their side jobs. ${ }^{[29,30]}$ Moreover, this study has indicated that Indonesian regulations/policies have not yet developed a diverse healthcare system (due to physician dominance), thus further limiting pharmacist roles.

The implementation of JKN in 2014 presents an opportunity to improve the utilisation of community pharmacies (more customers/prescriptions). Under the scheme, the government and IAI should consider establishing a formal agreement regarding basic services that should be available in the pharmacies; advanced services can be proposed once pilot studies can provide evidence of their benefits. While the current payment under JKN includes a very low prescription fee, ${ }^{[31]}$ the IAI should negotiate with the Government to ensure that pharmacists receive adequate remuneration for the provision of agreed basic services to create a stable environment for community pharmacy enabling it to remain viable. In turn, the JKN can be used to reinforce the requirement for community pharmacies to maintain pharmacist availability to be considered as eligible service providers, thus improving the quality of pharmacy services.

This study identified a need for PMRs and appropriate labelling. The IAI should consider developing specific standards and IT systems for dispensing to assist with labelling quality. The use of IT systems would also improve access to PMRs which is fundamental to provide direct patient care. While the Indonesian standard allows the use of pharmacy assistants to assist in the dispensary, ${ }^{[28]}$ and thus releasing pharmacists' time to do patient care, issues related to the supply and roles of pharmacy assistants warrant further considerations.

\section{Conclusion}

Issues related to the pharmacist-physician-patient relationships, pharmacy environment and external environment need to be addressed before Indonesian community pharmacists can provide pharmacy services for type 2 diabetes patients. The Government and IAI should prioritise their support in improving the pharmacy professional environment and facilities, particularly pharmacist availability during opening hours, and implementation of IT systems for labelling and PMRs. An appropriate remuneration system should also be established to create a stable environment for community pharmacies to develop new services. Once these are established, a close liaison with physicians and their governing bodies is essential to create more formal integration of community pharmacists within the health system.

\section{Declarations}

\section{Conflict of interest}

The Author(s) declare(s) that they have no conflicts of interest to disclose.

\section{Funding}

This research received no specific grant from any funding agency in the public, commercial or not-for-profit sectors.

\section{Acknowledgements}

We thank all the participants who took part in this study as well as the Ikatan Apoteker Indonesia (IAI; Indonesian Pharmacists Association) and staff from the Centre of Medicines Information and Pharmaceutical Care (CMIPC), Pharmacy Faculty, University of Surabaya, for their technical support in making this study possible.

\section{Authors' contributions}

YW made contributions to the design, supervised and participated in data collection, analysed data qualitatively, wrote the first draft of the report, and approved the final version for submission. BS and $\mathrm{JH}$ contributed to the conception and design of the study, analysis, interpretation of data, revisions to the manuscript and final approval of the version to be published. All Authors state that they had complete access to the study data that support the publication.

\section{References}

1. Badan Pusat Statistik (BPS), Badan Kependudukan dan Keluarga Berencana Nasional (BKKBN), and Kementrian Kesehatan Republik Indonesia (Kemenkes RI), and ICF Interna- tional. Indonesia Demographic and Health Survey 2012. Jakarta: BPS, BKKBN, Kemenkes RI, and ICF International, 2013.

2. International Diabetes Federation (IDF). IDF Diabetes Atlas 6th edn. [online] 2013. http://www.idf.org/
sites/default/files/EN_6E_Atlas_Full_0 .pdf (archived at http://www .webcitation.org/6U9H8Kztn accessed 17 November 2014).

3. Soewondo P et al. The DiabCare Asia 2008 study - outcomes on control and complications of type 2 diabetic 
patients in Indonesia. Med J Indones 2010; 19: 235-244.

4. Soewondo $\mathrm{P}$ et al. Challenges in diabetes management in Indonesia: a literature review. Global Health 2013; 9: 63.

5. Thornley T. Factors Affecting Service Delivery within Community Pharmacy in the United Kingdom. Nottingham: University of Nottingham, 2006.

6. Roberts A et al. Implementing cognitive services in community pharmacy: a review of facilitators used in practice change. Int J Pharm Pract 2006; 14: 163-170.

7. Herman M, Susyanty A. [An analysis of pharmacy services by pharmacist in community pharmacy]. Bul Penelit Sist Kesehat 2012; 15: 271-281.

8. Ngorsuraches S, Chen Li S. Thai pharmacists understanding, attitudes and perceived barriers related to providing pharmaceutical care. Am J Health Syst Pharm 2006; 63: 2144-2150.

9. Berbatis $\mathrm{C}$ et al. Enhanced pharmacy services, barriers and facilitators in Australia's community pharmacies: Australia's National Pharmacy Database Project. Int J Pharm Pract 2007; 15: 185-191.

10. Gastelurrutia $\mathrm{M}$ et al. Barriers for the implementation of cognitive services in Spanish community pharmacies. J Aten Prim 2007; 39: 465-472.

11. Gastelurrutia $M$ et al. Facilitators for practice change in Spanish community pharmacy. Pharm World Sci 2009; 31: 32-39.

12. Plake $\mathrm{K}$ et al. Barriers to community pharmacists' provision of diabetes care services in Iowa. J Pharm Technol 2007; 23: 327-338.

13. Roberts A et al. Practice change in community pharmacy: quantification of facilitators. Ann Pharmacother 2008; 42: 861-868.

14. Niquille A et al. Medication reviews led by community pharmacists in Switzerland: a qualitative survey to evaluate barriers and facilitators. Pharm Pract 2010; 8: 35-42.
15. Herman M et al. [Analysis of internal and external factors associated with a model of pharmacy-based enhanced services]. Bul Penelit Sist Kesehat, 2008; 11: 145-155.

16. Fang Y et al. Pharmacists' perception of pharmaceutical care in community pharmacy: a questionnaire survey in Northwest China. Health Soc Care Community 2011; 19: 189-197.

17. Pemerintah Kota Surabaya. [Demographic data]. [online] 2012. www .surabaya.go.id/profilkota/index.php ?id=22 (accessed 15 Jan 2015) [In Bahasa Indonesian].

18. Smith F. Research Methods in Pharmacy Practice. London: Pharmaceutical Press, 2002.

19. Wibowo Y. A model of Community Pharmacy-Based Service for Type 2 Diabetes in the Indonesian Setting. Perth: Curtin University, 2014.

20. Zhang Y, Wildemuth B. Thematic content analysis. In: Wildemuth B ed. Applications of Social Research Methods to Questions in Information and Library Science. Westport, CT: Libraries Unlimited, 2009; 308-319.

21. van Nes F et al. Language differences in qualitative research: is meaning lost in translation? Eur J Ageing 2010; 7: 313316.

22. Shenton A. Strategies for ensuring trustworthiness in qualitative research projects. Educ Inf 2004; 22: 63-75.

23. Holloway I. Qualitative writing. In: Holloway I ed. Qualitative Research in Health Care. Maidenhead: Open University Press, 2005; 270-286.

24. Asosiasi Perguruan Tinggi Farmasi Indonesia (APTFI). [Pharmacy curriculum - undergraduate program]. [online] 2008. http://aptfi.or.id/files/ kurikulum-inti-program-pendidikansarjana-farmasi.pdf (archived at http:// www.webcitation.org/6U9Hzjwew accessed 17 November 2014) [In Bahasa Indonesia].

25. Asosiasi Perguruan Tinggi Farmasi Indonesia (APTFI). [Pharmacy curriculum - pharmacist registration program]. [online] 2008. http:// aptfi.or.id/files/Kurikulum\%20

Program\%20Pendidikan\%20Apoteker .pdf (archived at http://www .webcitation.org/6U9J7s FKE accessed 17 November 2014) [In Bahasa Indonesia].

26. Muijrers $\mathrm{P}$ et al. Changing relationships: attitudes and opinions of general practitioners and pharmacists regarding the role of the community pharmacist. Pharm World Sci 2003; 25: 235 241.

27. Pemerintah Republik Indonesia. [Government Regulation Number 51 of 2009: Pharmacy practice]. Jakarta: Pemerintah Republik Indonesia, 2009.

28. Kementrian Kesehatan Republik Indonesia (Kemenkes RI). [Ministry of Health Decree Number 1027/MENKES/ SK/IX/2004: Standards for Pharmaceutical Care in Community Pharmacies]. Jakarta, 2006: Kemenkes RI.

29. Purwanti A et al. [Description of the implementation of standards for pharmacy services in community pharmacies in Jakarta in 2003]. Maj Ilmu Kefarmasian 2004; 1: 102-115.

30. Zurmatias R. Pharmaceutical Services in Community Pharmacy in Jakarta. Bangkok: Chulalongkorn University, 2007.

31. Kementrian Kesehatan Republik Indonesia (Kemenkes RI). [Circular Letter Number HK/MENKES/31/2014: Standards of Tariff for Health Services Providing in Primary and Secondary/Tertiary Healthcare Facilities within National Health Insurance Program]. Jakarta: Kemenkes RI, 2014.

\section{Supporting information}

Additional Supporting Information may be found in the online version of this article at the publisher's web-site:

Table S1 Consolidated criteria for reporting qualitative studies (COREQ) 32-item checklist. 


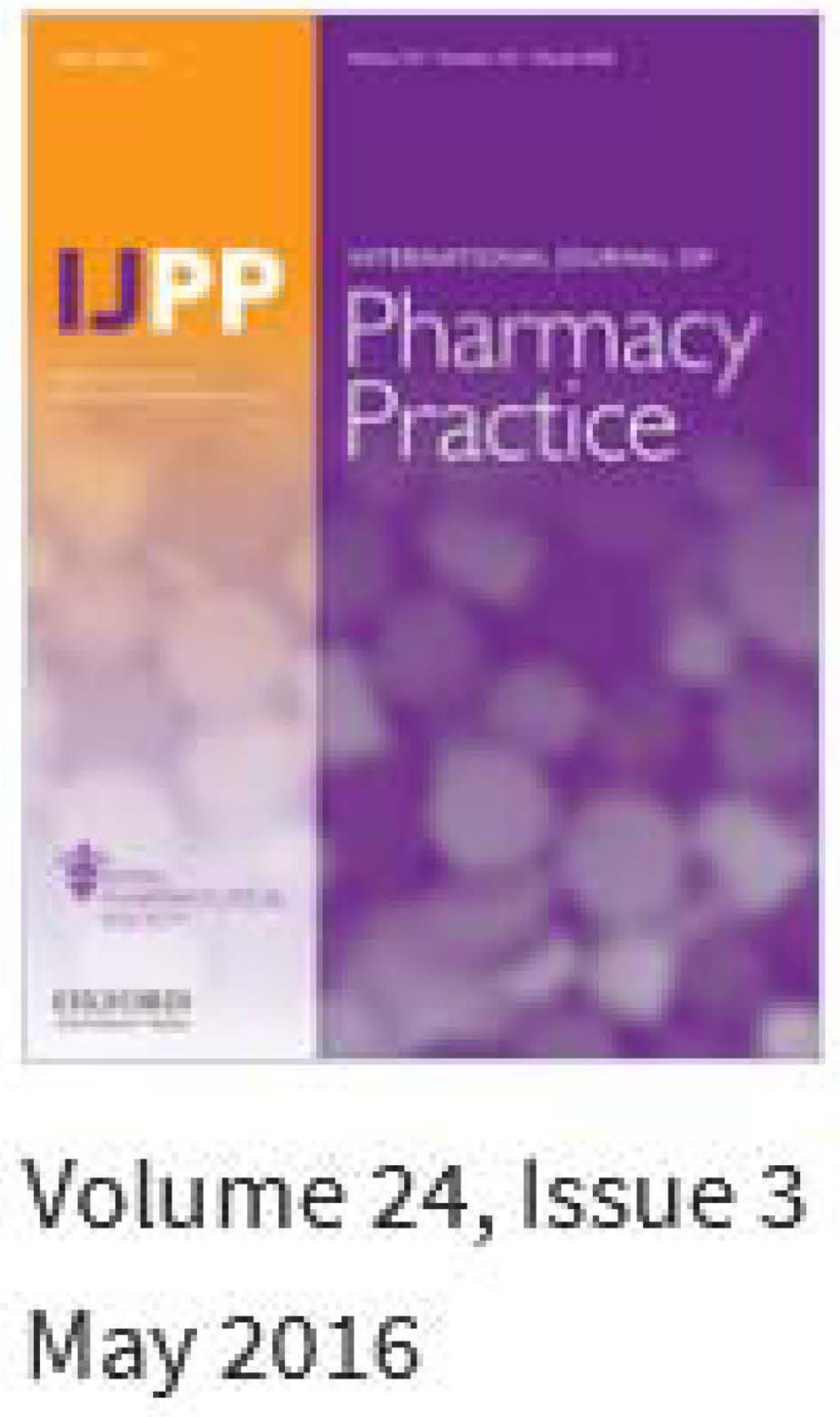


About Us

Ads by Google

Stop seeing this ad Why this ad?

\section{International Journal of Pharmacy Practice}

\section{COUNTRY \\ United Kingdom institutions in United Kingdom}

PUBLICATION TYPE

Journals

\section{SUBJECT AREA AND CATEGORY}

Health Professions Pharmacy

Medicine

Health Policy

Medicine (miscellaneous)

Public Health, Environmental and Occupational

Health

Pharmacology. Toxicology and Pharmaceutics Pharmaceutical Science

Ads by Google

Stop seeing this ad

Why this ad? of
PUBUSHER

Wiley-Blackwell
ISSN

09617671, 20427174
COVERAGE

1991-2020
INFORMATION

Homepage

How to publish in this journal

c.m.bond@abdn.ac.uk 


\section{SCOPE}

The International Journal of Pharmacy Practice (IJPP) is a Medline-indexed, peer reviewed, international journal. It is one of the leading journals publishing health services research in the context of pharmacy, pharmaceutical care, medicines and medicines management. Regular sections in the journal include, editorials, literature reviews, original research, personal opinion and short communications. Topics covered include: medicines utilisation, medicine management, medicines distribution, supply and administration, pharmaceutical services, professional and patient/lay perspectives, public health (including, e.g. health promotion, needs assessment, health protection) evidence based practice, pharmacy education. Methods include both evaluative and exploratory work including, randomised controlled trials, surveys, epidemiological approaches, case studies, observational studies, and qualitative methods such as interviews and focus groups. Application of methods drawn from other disciplines e.g. psychology, health economics, morbidity are especially welcome as are developments of new methodologies.

Q Join the conversation about this journal

\begin{tabular}{|c|c|}
\hline 2 & 3 \\
\hline Pharmacy Practice & $\begin{array}{l}\text { International Journal of } \\
\text { Clinical Pharmacy }\end{array}$ \\
\hline ESP & NLD \\
\hline $\begin{array}{l}73 \% \\
\text { similarity }\end{array}$ & $\begin{array}{l}61 \% \\
\text { similarity }\end{array}$ \\
\hline
\end{tabular}

Journal of Pharmaceutical Health Services Research GBR

\section{$53 \%$}

similarity options : ournal of Pharmacy Practic and Research USA

similarity

\section{Impact Factor Journal}

Speedy publication time is given high priority 


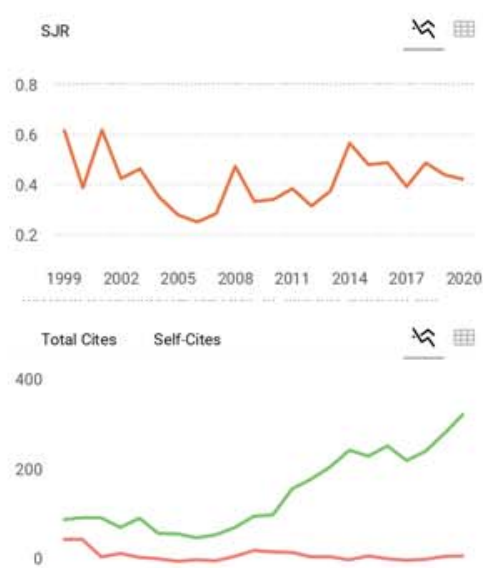

$\begin{array}{llllllll}1999 & 2002 & 2005 & 2008 & 2011 & 2014 & 2017 & 2020\end{array}$

\$International Collaboration

年囲

40

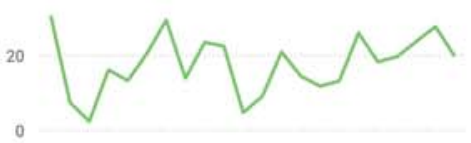

$\begin{array}{llllllll}1999 & 2002 & 2005 & 2008 & 2011 & 2014 & 2017 & 2020\end{array}$

International Journal of $\leftarrow$ Show this widget in Prour own website

Q2 Pharmaceuticat S|R $2020 \sim 20$

0.42 powered by scimagoir com cur own website

Just copy the code below and paste within your htm code:

$<$ href="https://www.scim
Total Documents

尔四

150

100

50

$\begin{array}{llllllll}1999 & 2002 & 2005 & 2008 & 2011 & 2014 & 2017 & 2020\end{array}$

External Cites per Doc Cites per Doc 施

18

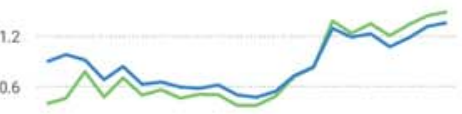

$\begin{array}{llllllll}1999 & 2002 & 2005 & 2008 & 2011 & 2014 & 2017 & 2020\end{array}$

Citable documents Non-citable documents th 400

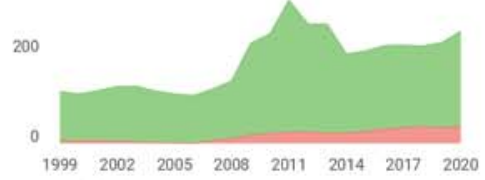

G SCImago Graphica

Explore, visually

communicate and make

sense of data with our new

free tool.

Get it

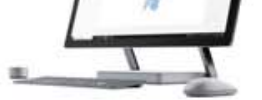

Citations per document

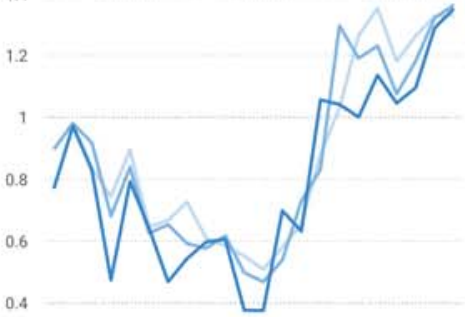

0.2

$\begin{array}{llllllll}1999 & 2002 & 2005 & 2008 & 2011 & 2014 & 2017 & 2020\end{array}$

Cites / Doc. (4 years)

Cites $/ D \propto$. (3 years)

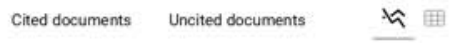
400

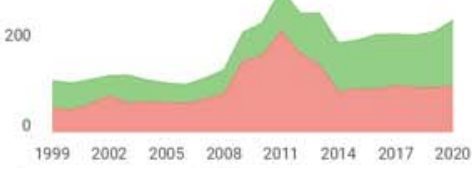

Impact Factor Journal

Speedy publication time is given high priority

Thieme Medical Publishers

Metrics based on Scopus@ data as of April 2021

Dear Hima,

thank you for contacting us.

Sorry to tell you that SCImago Journal \& Country Rank is not a journal. SUR is a portal with scientometric indicators of journals indexed in Elsevier/Scopus.

Unfortunately, we cannot help you with your request, we suggest you to visit the journal's

homepage or contact the journal's editorial staff, so they could inform you more deeply. Best Regards, SCImago Team 
Dear user, SCImago Journal and Country Rank uses Scopus data, our impact indicator is the SJR. Check our web to locate the journal (you can see it just above). We suggest you to consult the Journal Citation Report for other indicators (like Impact Factor) with a Web of Science data source. Best Regards, SCImago Team

Leave a comment

Name (wan not be pubilisheos)

The users of Scimago Journal \& Country Rank have the possibility to dialogue through comments linked to a specific journal. The purpose is to have a forum in which general doubts about the processes of publication in the journal, experiences and other issues derived from the publication of papers are resolved. For topics on particular articles, maintain the dialogue through the usual channels with your editor.

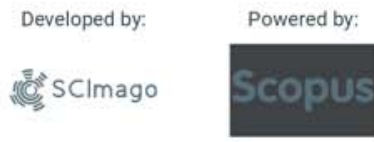

Follow us on @ScimagoJR

Scimago Lab, Copyright 2007-2020. Data Source: Scopus $₫$ 


\section{Source details}

\section{International Journal of Pharmacy Practice}

Scopus coverage years: from 1991 to Present

Publisher: Oxford University Press

ISSN: 0961-7671 E-ISSN: 2042-7174

Subject area: Medicine: General Medicine

Source type: Journal

View all documents >

Set document alert

$\square$ Save to source list Source Homepage
CiteScore 2020

2.4

SJR 2020

0.420

SNIP 2020

0.823 (i)

(i)

(i)

\section{CiteScore CiteScore rank \& trend Scopus content coverage}

i Improved CiteScore methodology

CiteScore 2020 counts the citations received in 2017-2020 to articles, reviews, conference papers, book chapters and data papers published in 2017-2020, and divides this by the number of publications published in 2017-2020. Learn more $>$

CiteScore 2020

$2.4=\frac{663 \text { Citations } 2017-2020}{271 \text { Documents } 2017-2020}$

Calculated on 05 May, 2021
CiteScoreTracker 2021 (i)

$2.7=\frac{674 \text { Citations to date }}{251 \text { Documents to date }}$

Last updated on 05 October, 2021 • Updated monthly

\section{CiteScore rank 2020 (i)}
Category
Rank Percentile

Medicine

L Generat Medicine

\#223/793

7lst

View CiteScore methodology $>$ CiteScore FAQ $>$ Add CiteScore to your site $\mathbb{O}$ 

About Scopus
Русский язык
Privacy matters
ELSEVIER Terms and conditions $\pi \quad$ Privacy policy $\pi$
Copyright (C) Elsevier B.V ז. All rights reserved. Scopus ${ }^{\circledR}$ is a registered trademark of Elsevier B.V.
We use cookies to help provide and enhance our service and tailor content. By continuing, you agree to the use
of cookies. 


\section{Editorial Board}

\section{Editor}

C Bond, Centre of Academic Primary Care, University of Aberdeen, UK

\section{Statistical Adviser}

A Lee, University of Aberdeen, UK

\section{Managing Editor}

Alice Shuttleworth

Email: Alice.Shuttleworth@rpharms.com

\section{Editorial Assistant}

Emma FitzGerald

Email: IJPP.EditorialOffice@oup.com

\section{Editorial Board}

A Avery, University of Nottingham, UK

J Barnes, University of Auckland, New Zealand

S I Benrimoj, University of Sydney, Australia

L Bero, University of California San Francisco, USA

K Bingefors, Uppsala University, Sweden

M Bouvy, SIR Institute for Pharmacy Practice and Policy, The Netherlands

C Bradley, University Coilege Cork, Ireland

J Brien, University of Sydney, Australia

T Chen, University of Sydney, Australia

B Chewning, University of Wisconsin, USA

A Cox, University of Birmingham, UK

$\mathrm{H}$ Enlund, Kuwait University, Kuwait

K Farris, University of Michigan, USA

C Gaither, University of Michigan, USA

J George, Monash University, Australia

K Hand, University of Southampton, UK

G Harding, Peninsula Medical School, UK

A Hartzema, University of Florida, USA

K Hassell, University of Manchester, UK

C Hughes, Queen's University of Belfast, UK

D John, Cardiff University, UK

J Jose, University of Nizwa, Oman

M King, Griffith University, Australia

J Krska, Liverpool John Moores University, UK 
D Latif, University of Charleston, USA

S Latter, University of Southampton, UK

L Mallet, University of Montreal, Canada

J McElnay, Queen's University of Belfast, UK

T Raynor, University of Leeds, UK

A Riewpaiboon, Mahidol University, Thailand

I Savage, University of London, UK

M Schaefer, Charité Universitätsmedizin Berlin, Germany

S Simoens, Katholieke Universiteit Leuven, Belgium

J Sheridan, University of Auckland, New Zealand

B Sleath, University of North Carolina, USA

F Smith, University of London, UK

W Soller, University of California San Francisco, USA

R Tamblyn, McGill University, Canada

J M Traulsen, University of Copenhagen, Denmark

I Truter, Nelson Mandela Metropolitan University, South Africa

R T Tsuyuki, Professor of Medicine, EPICORE Centre

$\mathrm{T}$ Walley, University of Liverpool, UK

M C Watson, University of Bath, UK

M Wazaify, University of Jordan, Jordan

A Wertheimer, Temple University, USA

B Williams, University of Dundee, $U K$

\section{Editorial Office}

Email: IJPP.Editorialoffice@oup.com 
Volume 24, Issue 3, May 2016

\section{EDITORIAL}

The pros and cons of E-cigarettes: a challenge for public health

Christine Bond

International Journol of Pharmacy Proctice, Volume 24, Issue 3, May 2016, Pages 147-148,

https://doi.org/10.1111/ijpp.12270

Extract $* \quad$ View article

\section{RESEARCH PAPER}

Implementing oral chemotherapy services in community pharmacies: a qualitative study of chemotherapy nurses' and pharmacists' views 1

Farida Butt, Emma Ream

International Journol of Pharmacy Practice, Volume 24, Issue 3, May 2016, Pages 149-159, https://doi.org/10.1111/ijpp.12237

Abstract * View article Supplementary data

Herbal and nutrient complementary medicines for weight loss: community pharmacists' practices, attitudes, recommendations, information and education needs ?

Meng-Wong Taing, Eunice Tze Xin Tan, Gail M Williams, Alexandra M Clavarino, Treasure M McGuire International Journal of Pharmacy Practice, Volume 24, Issue 3, May 2016, Pages 160-169, https://doi.org/10.1111/ijpp.12232

Abstract $\nabla$ View article

Delegation: a solution to the workload problem? Observations and interviews with community pharmacists in England 1 Victoria M Lea, Sarah A Corlett, Ruth M Rodgers

International Journol of Pharmocy Proctice, Volume 24, Issue 3, May 2016, Pages 170-179, https://doi.org/10.1111/ijpp.12230

Abstract $\nabla$ View article

Pharmacist and physician perspectives on diabetes service delivery within community pharmacies in Indonesia: a qualitative study Yosi Wibowo, Bruce Sunderland, Jeffery Hughes

International Journol of Pharmocy Proctice, Volume 24, Issue 3, May 2016, Pages 180-188, https://doi.org/10.1111/ijpp.12227

Abstract v View article Supplementary data 
Community pharmacy-based A1c screening: a Canadian model for diabetes care

John Papastergiou, Chris Folkins, Wilson Li

International Journol of Pharmacy Proctice, Volume 24, Issue 3, May 2016, Pages 189-195, https://doi.org/10.1111/ijpp.12228

Abstract $\vee$ View article

An evaluation of paediatric medicines reconciliation at hospital discharge into the community

Chi Huynh, lan Chi Kei Wong, Stephen Tomlin, Ellisha Halford, Yogini Jani ...

Internotional Journol of Pharmacy Proctice, Volume 24, Issue 3, May 2016, Pages 196-202, https://doi.org/10.1111/ijpp.12229

Abstract $\vee$ View article

Incidence and risk factors associated with iron deficiency anaemia among hospitalised Lebanese infants $\mathbb{B}$

Razan Ghattas Mhanna, Mohamad Rahal, Mohamad Iskandarani, Dalal Hammoudi

Internotional Journol of Pharmacy Proctice, Volume 24, Issue 3, May 2016, Pages 203-208, https://doi.org/10.1111/ijpp.12236

Abstract $*$ View article

Development of indicators to assess the quality of medicines reconciliation at hospital admission: an e-Delphi study Mohammed Sulaiman Aljamal, Darren Ashcroft, Mary P Tully

Internotional Journol of Pharmacy Proctice, Volume 24, Issue 3, May 2016, Pages 209-216, https://doi.org/10.1111/ijpp.12234

Abstract * View article

\section{SHORT COMMUNICATION}

Prevalence of non-adherence among psychiatric patients in Jordan, a cross sectional study

Tareq L Mukattash, Karem H Alzoubi, Ejlal Abu El-Rub, Anan S Jarab, Sayer I Al-Azzam ...

International Journol of Pharmacy Proctice, Volume 24, Issue 3, May 2016, Pages 217-221, https://doi.org/10.1111/ijpp.12239

Abstract * View article Supplementary data 